\title{
A new tool to screen patients with severe obstructive sleep apnea in the primary care setting: a prospective multicenter study
}

Patricia Peñacoba ${ }^{1,2^{*}}$ (1) Maria Antònia Llauger ${ }^{2,3}$, Ana María Fortuna ${ }^{1,2}$, Xavier Flor ${ }^{2,4}$, Gabriel Sampol ${ }^{2,5,6}$, Anna Maria Pedro-Pijoan ${ }^{7}$, Núria Grau ${ }^{6,8}$, Carme Santiveri ${ }^{9}$, Joan Juvanteny ${ }^{2,10}$, José Ignacio Aoiz ${ }^{11}$, Joan Bayó ${ }^{11}$, Patricia Lloberes ${ }^{5,6}$ and Mercè Mayos ${ }^{1,2,6}$ on behalf of the PASHOS Working Group

\begin{abstract}
Background: The coordination between different levels of care is essential for the management of obstructive sleep apnea (OSA). The objective of this multicenter project was to develop a screening model for OSA in the primary care setting.

Methods: Anthropometric data, clinical history, and symptoms of OSA were recorded in randomly selected primary care patients, who also underwent a home sleep apnea test (HSAT). Respiratory polygraphy or polysomnography were performed at the sleep unit to establish definite indication for continuous positive airway pressure (CPAP). By means of cross-validation, a logistic regression model (CPAP yes/no) was designed, and with the clinical variables included in the model, a scoring system was established using the $\beta$ coefficients (PASHOS Test). In a second stage, results of HSAT were added, and the final accuracy of the model was assessed.
\end{abstract}

Results: 194 patients completed the study. The clinical test included the body mass index, neck circumference and observed apneas during sleep (AUC $0.824,95 \% \mathrm{Cl} 0.763-0.886, P<0.001$ ). In a second stage, the oxygen desaturation index (ODI) of 3\% (ODI3\% $\geq 15 \%$ ) from the HSAT was added (AUC 0.911, 95\% Cl 0.863-0.960, $P<0.001$ ), with a sensitivity of $85.5 \%$ (95\% Cl 74.7-92.1) and specificity of $67.8 \%$ (95\% Cl 55.1-78.3).

Conclusions: The use of this model would prevent referral to the sleep unit for $55.1 \%$ of the patients. The two-stage PASHOS model is a useful and practical screening tool for OSA in primary care for detecting candidates for CPAP treatment.

Clinical Trial Registration Registry: ClinicalTrials.gov; Name: PASHOS Project: Advanced Platform for Sleep Apnea Syndrome Assessment; URL: https://clinicaltrials.gov/ct2/show/NCT02591979; Identifier: NCT02591979. Date of registration: October 30, 2015.

Keywords: Obstructive sleep apnea, Continuous positive airway pressure (CPAP), Primary healthcare, Sleep unit, Screening model, Home sleep apnea test

*Correspondence: ppenacoba@santpau.cat

1 Sleep Unit, Department of Respiratory Diseases, Hospital de La Santa Creu I Sant Pau, Universitat Autònoma de Barcelona, Barcelona, Spain Full list of author information is available at the end of the article

\begin{abstract}
Background
Obstructive sleep apnea (OSA) is a breathing disorder with high and increasing prevalence [1] and important deleterious effect on the patient's health and quality of life [2-5]. There is a wide consensus about the need for involvement of all healthcare levels especially primary
\end{abstract}

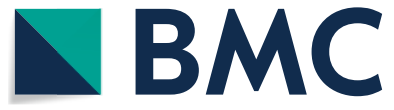

(c) The Author(s) 2022. Open Access This article is licensed under a Creative Commons Attribution 4.0 International License, which permits use, sharing, adaptation, distribution and reproduction in any medium or format, as long as you give appropriate credit to the original author(s) and the source, provide a link to the Creative Commons licence, and indicate if changes were made. The images or other third party material in this article are included in the article's Creative Commons licence, unless indicated otherwise in a credit line to the material. If material is not included in the article's Creative Commons licence and your intended use is not permitted by statutory regulation or exceeds the permitted use, you will need to obtain permission directly from the copyright holder. To view a copy of this licence, visit http://creativecommons.org/licenses/by/4.0/. The Creative Commons Public Domain Dedication waiver (http://creativeco mmons.org/publicdomain/zero/1.0/) applies to the data made available in this article, unless otherwise stated in a credit line to the data. 
care in the management of OSA [6, 7]. The participation of primary care professionals may contribute to improve underdiagnosis of OSA [8], which is particularly relevant because of conclusive evidence of the beneficial effects of continuous positive airway pressure (CPAP) on the overall health and prognosis of the patients [9]. In this context, primary care professionals play a double role. On one hand, to identify patients with severe OSA who should be referred to a specialized sleep unit for treatment and follow-up. On the other hand, to identify patients with mild-moderate OSA who can be managed in primary care, thus preventing unnecessary referrals and workload for sleep units. Different strategies with variable results have been proposed to meet this double objective, including the use of questionnaires alone [10-13] or combined with simplified models of home sleep apnea test (HSAT) [14-16], or strategies in which primary care physicians assume a central role in the care of patients with OSA [17-21]. The ideal model probably includes a coordinated network between different levels of care, adapted to the health care characteristics of the region and workload of the different settings, and able to be applicable to the broad spectrum of OSA phenotypes.

The PASHOS project (PASHOS is the Spanish acronym of Advanced Platform for Sleep Apnea Assessment) is a multicenter study conceived for the implementation of an inter-level working model, coordinated between primary care and sleep units. Previous development of the PASHOS project included specific training of primary care professionals (physicians and registered nurses), establishment of inter-level network tools [22] and analysis of primary care and sleep unit agreement in management decisions for OSA patients [23]. A moderate level of concordance on diagnostic classification between primary care physicians and sleep specialists was found, there was substantial agreement in patients with severe OSA who were candidates for CPAP therapy [23]. However, the overall sensitivity for detecting candidates for CPAP treatment by primary care physicians was only $62.2 \%$ [23]. Therefore, the development of a screening tool that would help in the clinical assessment and improve the ability to identify patients with OSA in the primary care setting seems justified. The objective of this study was to develop a two-stage screening model based on a clinical questionnaire and a HSAT, to detect patients with severe OSA who are candidates for treatment with CPAP.

\section{Methods}

\section{Design and participants}

This was a prospective, multicenter study with the participation of six primary health care centers and four sleep units from the urban area of Barcelona (Spain). The methodology of the study has been previously described in detail [22]. The PASHOS project has been approved by the Clinical Research Ethics Committee of the 10 participating centers, and written informed consent was obtained from all patients. The study was registered at ClinicalTrials.gov (identifier NCT02591979).

Between May 2015 and May 2018, men and women aged $\geq 18$ and $\leq 75$ years who visited a participating primary care center for any reason, were consecutively included according to a randomized schedule. Exclusion criteria were as follows: previous diagnosis of OSA, chronic insomnia ( $<5 \mathrm{~h}$ of sleep/day), cognitive impairment or psychophysical inability to perform the HSAT, acute or unstable cardiovascular or cerebrovascular disease, neuromuscular disease, moderate-to-severe chronic obstructive pulmonary disease (COPD) $\left(\mathrm{FEV}_{1} /\right.$ $\mathrm{FVC}<0.7 \%$ and $\mathrm{FEV}_{1}<50 \%$ predicted), and relevant respiratory comorbidity that may interfere with arterial blood saturation measurements.

\section{Study procedures and data collection}

The two-stage study design included a clinical assessment at the primary care center and a HSAT. At the patient's visit in the primary care center, the following data were recorded: sociodemographic (age and sex), anthropometric (weight, height, body mass index [BMI], and neck, waist and hip circumference), history of relevant diseases and cardiovascular risk factors, forced spirometry, clinical history directed to assessment of sleep breathing disorders, daytime sleepiness using the Epworth sleepiness scale [24], the Berlin questionnaire [25], OSA50 questionnaire [14] and the STOP-Bang sleep apnea questionnaire [11].

The clinical probability of OSA based on scores of the Berlin questionnaire [25] was used to assess the prevalence of patients with low and high risk of OSA. To ensure a balanced sample between patients with low and high risk, according to the method proposed by Chai-Coetzer et al. [14] and considering an expected prevalence of OSA of $25-30 \%$ in primary care [25], all patients in the high-risk category and, randomly, 1 out of 2 patients in the low-risk underwent a HSAT. In all cases, sleep studies were performed using a self-applied Sibelmed Screen $\& \mathrm{Go}^{\circledR}$ polygraph device (Bitmed, Sibelgroup, Barcelona, Spain), with a 2-channel monitor: nasal cannula for airflow measure and oximetry. The device also provided body position. The primary care nurses assessed the quality of the HSAT and removed the periods of poor signaling (artifacts or lost signal). The minimum valid recording time was $5 \mathrm{~h}$, and the sleep study was repeated if a poor signal acquisition was detected or the recording time was less than $5 \mathrm{~h}$. Variables recorded included peripheral oxygen saturation $\left(\mathrm{SpO}_{2}\right)$, falls in $\mathrm{SpO}_{2} \geq 3 \%$ 
(oxygen desaturation index-ODI3\%) and $\geq 4 \%$ (ODI4\%) per hour of recording, and time spent in the supine position. A hypopnea was defined as an airflow reduction of $\geq 30 \%$ but $<90 \%$ lasting at least $10 \mathrm{~s}$, with a $\geq 3 \%$ drop in oximetry, and an apnea was defined as an absence of airflow or $\geq 90 \%$ reduction for $\geq 10 \mathrm{~s}$. Cut-off points for AHI were $5-15$ for mild OSA, $>15$ and $<30$ for moderate OSA, and $\geq 30$ for severe OSA.

All patients independent of the clinical probability of OSA and within 3 months after HSAT, were referred to the sleep unit and underwent a respiratory polygraphy or conventional polysomnography according to standard practice $[26,27]$. Specialists at the sleep unit with all clinical documentation available established a final diagnosis and therapeutic decision regarding whether or not patients were candidates for CPAP therapy. The diagnosis of OSA and indication of CPAP treatment were made according to clinical practice guidelines [26, 27].

\section{Statistical analysis}

The sample size was estimated considering a minimum prevalence of OSA of $25 \%$ in the population attended to in the primary care setting [25]. Assuming a loss of $15 \%$ at follow-up and an alpha error of $5 \%$, a total sample of 162 patients was needed to detect a sensitivity of $90 \%$ in the validation process. Categorical variables are expressed as frequencies and percentages, and continuous variables as mean, standard deviation (SD) and $95 \%$ confidence interval $(\mathrm{CI})$. Bivariate analysis included the chi-square test $\left(X^{2}\right)$ test or the Fisher's exact probability test for categorical data, and the Student's $t$ test or the Mann-Whitney $U$ test for continuous data according to the conditions of application.

Development of the screening predictive model was made according to a cross-validation procedure, with the whole sample available for estimation of the model and further validation. Thus, all clinical variables were included in a multivariate logistic regression analysis, in which indication of CPAP treatment (yes/no) made by sleep specialists was the dependent variable. Categorical variables of clinical questionnaires were dichotomously recodified. In order to simplify the predictive clinical screening model and facilitate its applicability in daily practice, a system of stratification and scoring according to $\beta$ coefficients of the logistic regression model [13] was developed. The variance inflation factor (VIF) was used to assess multicollinearity of the model, with $\mathrm{VIF}<5$ indicating a complete absence of collinearity [28]. Diagnostic accuracy of clinical variables and HSAT was assessed with the area under the curve (AUC) of the receiver operating characteristic (ROC) curve.

A first analysis was performed including only the clinical variables. For each of the final scores, sensitivity, specificity, positive and negative predictive values, overall accuracy, likelihood ratio, odds ratio, and the post-test probability with the $95 \% \mathrm{CI}$ were calculated. The cut-off point of maximum sensitivity and moderate specificity was chosen. The same data was calculated for the results of the Epworth sleepiness scale, the Berlin questionnaire, the STOP-Bang sleep apnea questionnaire, and the OSA50 questionnaire. In a second analysis, the ROC curve and the AUC were recalculated after including variables collected in the HSAT, such as apnea-hypopnea index (AHI), ODI3\% and ODI4\%. Statistical significance was set at $P<0.05$. Statistical analyses were performed using the statistical software IBM-SPSS version 26.0 for Windows.

\section{Results}

\section{Characteristics of participants}

A total of 1036 patients were assessed by primary care physicians, 466 (45\%) of which were eligible and agreed to take part in the study. A total of 249 (53.4\%) patients underwent HSAT. There were no significant differences between patients with low clinical probability of OSA based on scoring of the Berlin questionnaire that were randomized to or not to perform a HSAT (Table S1, Supplementary material). Finally, 194 (41.6\%) patients completed the second stage with a respiratory polygraphy or conventional polysomnography at the sleep unit, and the definitive diagnosis and therapeutic decision was established. Of the total 194 patients who completed the study, 126 (64.9\%) were not considered candidates for CPAP therapy, whereas the remaining $68(35.0 \%)$ were candidates for CPAP treatment. The flow chart of the study population is shown in Fig. 1. The clinical characteristics of patients in the overall study population and in the groups of candidates and non-candidates for CPAP therapy are shown in Table 1.

\section{Model based on clinical variables (PASHOS test)}

After logistic regression analysis (candidate for CPAP treatment, yes or no) and taking into account all clinical data, the final model included the following three variables: BMI, neck circumference, and the question "Have you been told that you repeatedly stop breathing when asleep?". The collinearity between these three variables was excluded. The AUC of the ROC curve was 0.824 (95\% CI 0.763-0.886). Results of the logistic regression analysis and scores assigned to each variable are shown in Table 2. The final screening questionnaire, named the PASHOS Test (Table S2, Supplementary material), was scored between 0 and 11 (higher scores indicated higher probability of CPAP treatment for OSA). The AUC of the ROC curve for discriminating patients who were candidates or not for CPAP treatment was 0.824 (95\% 


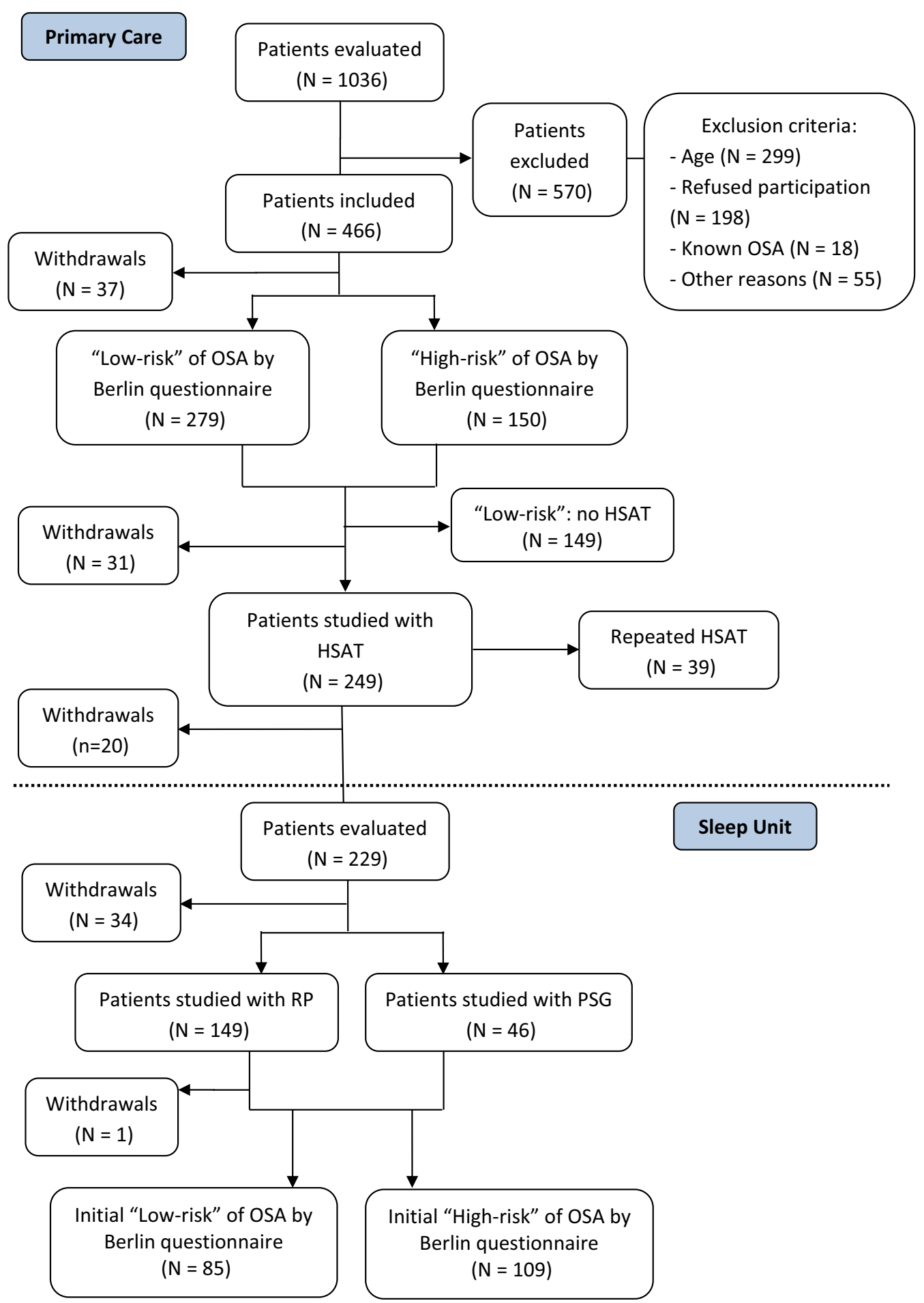

Fig. 1 Flow chart of the study population (OSA: obstructive sleep apnea; HSAT: home sleep apnea test; RP: respiratory polygraphy; PSG; polysomnography)

CI 0.764-0.884), almost identical to that of the regression model. The diagnostic accuracy of the test according to different cut-off values is shown in Table 3. A cut-off value of $\geq 5$ classified a patient as candidate for CPAP treatment with a sensitivity of $92.6 \%$ (95\% CI 83.9-96.8) and a specificity of $53.2 \%$ (95\% CI $44.5-61.7)$, so that with a test score $<5$, only 5 patients were excluded who were finally candidates for CPAP treatment. 
Table 1 Characteristics of patients and results of sleep studies according indication of CPAP treatment by the sleep specialist

\begin{tabular}{|c|c|c|c|c|}
\hline Variables & All patients $(n=194)$ & $\begin{array}{l}\text { Non-candidates for CPAP } \\
(n=126)\end{array}$ & $\begin{array}{l}\text { Candidates for CPAP } \\
(\mathrm{n}=68)\end{array}$ & $P$ value \\
\hline Men:women & 106:88 & $56: 70$ & $50: 18$ & $<0.001$ \\
\hline Age, years, mean (SD) & $55.9(12)$ & $55.1(12.3)$ & $57.4(11.4)$ & 0.202 \\
\hline \multicolumn{5}{|l|}{ Anthropometric variables, mean (SD) } \\
\hline Body mass index, $\mathrm{kg} / \mathrm{m}^{2}$ & $29.2(5.1)$ & $27.7(4.5)$ & $32(5.2)$ & $<0.001$ \\
\hline Neck circumference, cm & $38.2(4.6)$ & $36.7(4.2)$ & $41.1(4)$ & $<0.001$ \\
\hline Waist circumference, $\mathrm{cm}$ & $98.7(13.7)$ & $94(12.6)$ & $107.4(11.2)$ & $<0.001$ \\
\hline Hip circumference, $\mathrm{cm}$ & $106.6(10.5)$ & $103.8(10)$ & $111.8(9.4)$ & $<0.001$ \\
\hline Waist-hip ratio & $0.92(0.11)$ & $0.9(0.1)$ & $0.94(0.12)$ & 0.008 \\
\hline \multicolumn{5}{|l|}{ Comorbidities } \\
\hline Hypertension & $68(35.1)$ & $36(28.6)$ & $32(47.1)$ & 0.010 \\
\hline Diabetes mellitus & $35(18)$ & $23(18.3)$ & $12(17.6)$ & 0.008 \\
\hline Dyslipidemia & $70(36.1)$ & $44(34.9)$ & $26(38.2)$ & 0.656 \\
\hline Depression & $18(9.3)$ & $10(7.9)$ & $8(11.8)$ & 0.381 \\
\hline Anxiety & $35(18)$ & $23(18.3)$ & $12(17.6)$ & 0.916 \\
\hline Stroke & $2(1)$ & $2(1.6)$ & $0(0)$ & 0.542 \\
\hline Arrhythmia & $7(3.6)$ & $2(1.6)$ & $5(7.4)$ & 0.053 \\
\hline Peripheral artery disease & $8(4.1)$ & $4(3.2)$ & $4(5.9)$ & 0.365 \\
\hline Hypothyroidism & $12(6.2)$ & $7(5.6)$ & $5(7.4)$ & 0.620 \\
\hline Heart disease & $13(6.7)$ & $6(4.8)$ & $7(10.3)$ & 0.141 \\
\hline Active smoking & $44(22.7)$ & $27(21.4)$ & $17(25)$ & 0.847 \\
\hline Alcohol consumption & $69(35.9)$ & $38(30.4)$ & $31(46.3)$ & 0.029 \\
\hline \multicolumn{5}{|l|}{ Spirometry, mean (SD) } \\
\hline $\mathrm{FEV}_{1}, \%$ & $90.6(13.8)$ & $91.5(14)$ & $89(13.5)$ & 0.236 \\
\hline FVC, \% & $92(14.9)$ & $92.3(15.1)$ & $91.5(14.6)$ & 0.730 \\
\hline Epworth sleepiness scale, mean (SD) & $7.8(5)$ & $7.2(4.6)$ & $8.8(5.5)$ & 0.031 \\
\hline \multicolumn{5}{|l|}{ Patients with low/high risk of OSA } \\
\hline Berlin questionnaire, $n=194$ & $85 / 109$ & $65 / 61$ & $20 / 48$ & \\
\hline STOP-Bang, $n=193$ & $57 / 136$ & $49 / 76$ & $8 / 60$ & \\
\hline OSA50, $n=185$ & $44 / 141$ & $39 / 80$ & $5 / 61$ & \\
\hline Epworth scale score $\geq 11, n=193$ & $142 / 51$ & $101 / 24$ & $41 / 27$ & \\
\hline \multicolumn{5}{|l|}{ HSAT, mean (SD) } \\
\hline Recording time, min & $414(84.8)$ & $418.3(87.4)$ & $406(79.9)$ & 0.334 \\
\hline $\mathrm{AHI}$ & $13.7(15.4)$ & $7.7(7.5)$ & $24.9(19.5)$ & $<0.001$ \\
\hline AHI supine & $24.2(23.2)$ & $15(16)$ & $41.3(24.8)$ & $<0.001$ \\
\hline Oxygen saturation $\left(\mathrm{SpO}_{2}\right)$ & $92.5(3.2)$ & $93.2(2.2)$ & $91.3(4.1)$ & $<0.001$ \\
\hline СТ90\% & $11.3(19.5)$ & $7.6(18)$ & $18.3(20.6)$ & $<0.001$ \\
\hline ODI3\% & $18.5(16.3)$ & $10.9(8.3)$ & $32.7(17.9)$ & $<0.001$ \\
\hline ODI4\% & $12.9(14.7)$ & $6.1(6.1)$ & $25.8(17.4)$ & $<0.001$ \\
\hline \multicolumn{5}{|l|}{ RP or conventional PSG, mean (SD) } \\
\hline Recording time, min & $463(58.2)$ & $462.3(50.8)$ & $464.2(70.2)$ & 0.829 \\
\hline $\mathrm{AHI}$ & $21.3(19.7)$ & $10.1(7.4)$ & $42.1(18.5)$ & $<0.001$ \\
\hline AHI supine & $24.3(21.6)$ & $12.9(10.6)$ & $47.2(20)$ & $<0.001$ \\
\hline Oxygen saturation $\left(\mathrm{SpO}_{2}\right)$ & $93.5(2)$ & $94.1(1.7)$ & $92.2(2)$ & $<0.001$ \\
\hline СТ90\% & $7.1(13.8)$ & $2.9(9.9)$ & $16.4(0.1)$ & $<0.001$ \\
\hline ODI3\% & $18.9(18.2)$ & $8.6(6.5)$ & $34.9(19.1)$ & $<0.001$ \\
\hline ODI4\% & $13.3(15.7)$ & $5.2(5.4)$ & $27.6(17.7)$ & $<0.001$ \\
\hline
\end{tabular}


Table 1 (continued)

saturations below 90\%; ODI3\%: oxygen desaturation index of 3\%; ODI4\%: oxygen desaturation index of 4\%; RP: respiratory polygraphy; PSG: polysomnography

Table 2 Results of multivariate analysis with stratification of variables and scores assigned to each variable in the PASHOS Test

\begin{tabular}{|c|c|c|c|c|c|c|}
\hline Variables & Coefficient ( $\beta$ ) & Standard error & Wald $\left(x^{2}\right)$ & $P$ value & Odds ratio $(95 \% \mathrm{Cl})$ & $\begin{array}{l}\text { Scores } \\
\text { (PASHOS } \\
\text { Test) }\end{array}$ \\
\hline \multicolumn{7}{|c|}{ Neck circumference, cm } \\
\hline$\leq 35$ & Reference & & & & & 0 \\
\hline$>35$ and $\leq 41$ & 1.472 & 0.545 & 7.300 & 0.007 & $4.359(1.5-12.68)$ & 3 \\
\hline$>41$ & 2.466 & 0.605 & 16.621 & $<0.001$ & $11.771(3.6-38.47)$ & 5 \\
\hline \multicolumn{7}{|l|}{$\mathrm{BMI}, \mathrm{kg} / \mathrm{m}^{2}$} \\
\hline$\leq 26$ & Reference & & & & & 0 \\
\hline$>26$ and $\leq 30$ & 1.215 & 0.585 & 4.316 & 0.038 & $3.369(1.07-10.6)$ & 2 \\
\hline$>30$ and $\leq 33$ & 1.587 & 0.610 & 6.763 & 0.009 & $4.887(1.48-16.15)$ & 3 \\
\hline$>33$ & 1.949 & 0.632 & 9.498 & 0.002 & $7.021(2.03-24.24)$ & 4 \\
\hline \multicolumn{7}{|c|}{ Breathing pauses during sleep } \\
\hline No & Reference & & & & & 0 \\
\hline Yes & 0.942 & 0.379 & 6.171 & $<0.001$ & $2.566(1.22-5.4)$ & 2 \\
\hline
\end{tabular}

BMI: body mass index; Cl: confidence interval

Table 3 Diagnostic accuracy of the PASHOS Test according to different cut-off values

\begin{tabular}{|c|c|c|c|c|c|c|c|c|c|}
\hline $\begin{array}{l}\text { PASHOS } \\
\text { Test cut-off } \\
\text { value }\end{array}$ & $\begin{array}{l}\text { Sensitivity } \\
\%(95 \% \mathrm{Cl})\end{array}$ & $\begin{array}{l}\text { Specificity } \\
\%(95 \% \text { Cl) }\end{array}$ & $\begin{array}{l}\text { Positive } \\
\text { predictive } \\
\text { value \% } \\
(95 \% \mathrm{Cl})\end{array}$ & $\begin{array}{l}\text { Negative } \\
\text { predictive } \\
\text { value } \% \\
(95 \% \mathrm{Cl})\end{array}$ & $\begin{array}{l}\text { Overall } \\
\text { accuracy \% } \\
(95 \% \mathrm{Cl})\end{array}$ & $\begin{array}{l}\text { Positive } \\
\text { likelihood } \\
\text { ratio (95\% } \\
\mathrm{Cl})\end{array}$ & $\begin{array}{l}\text { Negative } \\
\text { likelihood } \\
\text { ratio }(95 \% \\
\mathrm{Cl})\end{array}$ & $\begin{array}{l}\text { Odds ratio } \\
(95 \% \mathrm{Cl})\end{array}$ & $\begin{array}{l}\text { Post-test } \\
\text { probability \% } \\
(95 \% \mathrm{Cl})\end{array}$ \\
\hline$\geq 2$ & $\begin{array}{l}98.5 \\
(92.1-99.7)\end{array}$ & $\begin{array}{l}11.9 \\
(7.3-18.7)\end{array}$ & $\begin{array}{l}37.6 \\
(30.9-44.9)\end{array}$ & $\begin{array}{l}93.8 \\
(71.1-98.9)\end{array}$ & $\begin{array}{l}42.2 \\
(35.5-49.3)\end{array}$ & $\begin{array}{l}1.11 \\
(1.04-1.2)\end{array}$ & $\begin{array}{l}0.12 \\
(0.02-0.92)\end{array}$ & $\begin{array}{l}9.05 \\
(1.17-70.1)\end{array}$ & $\begin{array}{l}31.2(35.5- \\
38.8)\end{array}$ \\
\hline$\geq 3$ & $\begin{array}{l}98.5 \\
(91.1-99.7)\end{array}$ & $\begin{array}{l}27.0 \\
(20-35.3)\end{array}$ & $\begin{array}{l}42.1 \\
(34.7-49.9)\end{array}$ & $\begin{array}{l}97.1 \\
(85.5-99.5)\end{array}$ & $\begin{array}{l}52.1 \\
(45.1-59.0)\end{array}$ & $\begin{array}{l}1.35 \\
(1.21-1.51)\end{array}$ & $\begin{array}{l}0.05 \\
(0.01-0.39)\end{array}$ & $\begin{array}{l}24.76 \\
(3.3-185.4)\end{array}$ & $\begin{array}{l}41.7(39.0- \\
44.4)\end{array}$ \\
\hline$\geq 4$ & $\begin{array}{l}95.6 \\
(87.8-98.5)\end{array}$ & $\begin{array}{l}46.0 \\
(37.6-54.7)\end{array}$ & $\begin{array}{l}48.9 \\
(40.5-57.3)\end{array}$ & $\begin{array}{l}95.1 \\
(86.5-98.3)\end{array}$ & $\begin{array}{l}63.4 \\
(56.4-69.9)\end{array}$ & $1.77(1.5-2.1)$ & $\begin{array}{l}0.1 \\
(0.03-0.29)\end{array}$ & $\begin{array}{l}18.48 \\
(5.8-58.2)\end{array}$ & $\begin{array}{l}48.4(44.2- \\
52.6)\end{array}$ \\
\hline$\geq 5$ & $\begin{array}{l}92.6 \\
(83.9-96.8)\end{array}$ & $\begin{array}{l}53.2 \\
(44.5-61.7)\end{array}$ & $\begin{array}{l}51.6 \\
(42.9-60.3)\end{array}$ & $\begin{array}{l}93.1 \\
(84.8-97.0)\end{array}$ & $\begin{array}{l}67.0 \\
(60.1-73.2)\end{array}$ & $\begin{array}{l}1.98 \\
(1.62-2.41)\end{array}$ & $\begin{array}{l}0.14 \\
(0.06-0.33)\end{array}$ & $\begin{array}{l}13.31 \\
(5.54-37)\end{array}$ & $\begin{array}{l}51.1(46.2- \\
56.1)\end{array}$ \\
\hline$\geq 6$ & $\begin{array}{l}79.4 \\
(68.4-87.3)\end{array}$ & $\begin{array}{l}69.8 \\
(61.3-77.2)\end{array}$ & $\begin{array}{l}58.7 \\
(48.5-68.2)\end{array}$ & $\begin{array}{l}86.3 \\
(78.3-91.6)\end{array}$ & $\begin{array}{l}73.2 \\
(66.6-78.9)\end{array}$ & $\begin{array}{l}2.63 \\
(1.97-3.53)\end{array}$ & $\begin{array}{l}0.29 \\
(0.18-0.48)\end{array}$ & $\begin{array}{l}8.93 \\
(4.46-17.9)\end{array}$ & $\begin{array}{l}58.2(51.0- \\
65.1)\end{array}$ \\
\hline$\geq 7$ & $\begin{array}{l}70.6 \\
(58.9-80.1)\end{array}$ & $\begin{array}{l}77.0 \\
(68.9-83.5)\end{array}$ & $\begin{array}{l}62.3 \\
(51.2-73.3)\end{array}$ & $\begin{array}{l}82.9 \\
(75.1-88.7)\end{array}$ & $\begin{array}{l}74.7 \\
(68.2-80.3)\end{array}$ & $\begin{array}{l}3.07 \\
(2.15-4.37)\end{array}$ & $\begin{array}{l}0.38 \\
(0.26-0.56)\end{array}$ & $\begin{array}{l}8.02 \\
(4.14-15.6)\end{array}$ & $\begin{array}{l}61.9(53.2- \\
69.8)\end{array}$ \\
\hline$\geq 8$ & $\begin{array}{l}52.9 \\
(41.2-64.3)\end{array}$ & $\begin{array}{l}85.7 \\
(78.5-90.8)\end{array}$ & $\begin{array}{l}66.7 \\
(53.4-77.8)\end{array}$ & $\begin{array}{l}77.1 \\
(69.5-83.3)\end{array}$ & $\begin{array}{l}74.2 \\
(67.6-79.9)\end{array}$ & $\begin{array}{l}3.71 \\
(2.29-6.01)\end{array}$ & $\begin{array}{l}0.55 \\
(0.42-0.71)\end{array}$ & $\begin{array}{l}6.75 \\
(3.4-13.4)\end{array}$ & $\begin{array}{l}66.2(54.7- \\
76.1)\end{array}$ \\
\hline$\geq 9$ & $\begin{array}{l}44.1 \\
(32.9-55.9)\end{array}$ & $\begin{array}{l}91.3 \\
(85.0-95.1)\end{array}$ & $\begin{array}{l}73.2 \\
(58.1-84.3)\end{array}$ & $\begin{array}{l}75.2 \\
(67.8-81.3)\end{array}$ & $\begin{array}{l}74.7 \\
(68.2-80.3)\end{array}$ & $\begin{array}{l}5.05 \\
(2.71-9.44)\end{array}$ & $\begin{array}{l}0.61 \\
(0.49-0.76)\end{array}$ & $\begin{array}{l}8.25 \\
(3.81-17.8)\end{array}$ & $\begin{array}{l}72.8(58.9- \\
83.3)\end{array}$ \\
\hline$\geq 10$ & $\begin{array}{l}20.6 \\
(12.7-31.6)\end{array}$ & $\begin{array}{l}98.4 \\
(94.4-99.6)\end{array}$ & $\begin{array}{l}87.5 \\
(64.0-96.5)\end{array}$ & $\begin{array}{l}69.7 \\
(62.6-75.9)\end{array}$ & $\begin{array}{l}71.1 \\
(66.4-77.1)\end{array}$ & $\begin{array}{l}13.0 \\
(3.04-55.4)\end{array}$ & $\begin{array}{l}0.80 \\
(0.71-0.91)\end{array}$ & $\begin{array}{l}16.1 \\
(3.5-73.2)\end{array}$ & $\begin{array}{l}87.3(61.6- \\
96.7)\end{array}$ \\
\hline 11 & $\begin{array}{l}14.7 \\
(8.2-25.0)\end{array}$ & $\begin{array}{l}99.2 \\
(95.6-99,9)\end{array}$ & $\begin{array}{l}90.9 \\
(62.3-98.4)\end{array}$ & $\begin{array}{l}68.3 \\
(61.2-74.6)\end{array}$ & $\begin{array}{l}69.6 \\
(62.8-75.6)\end{array}$ & $\begin{array}{l}18.5 \\
(2.4-141.7)\end{array}$ & $\begin{array}{l}0.86 \\
(0.78-0.95)\end{array}$ & $\begin{array}{l}21.6 \\
(2.7-172.4)\end{array}$ & $\begin{array}{l}90.7(56.2- \\
98.7)\end{array}$ \\
\hline
\end{tabular}

Cl: confidence interval

The diagnostic accuracy of the PASHOS Test as compared with results of the Epworth sleepiness scale, Berlin questionnaire, STOP-Bang sleep apnea test, and OSA50 questionnaire is shown in Fig. 2. The AUC of the ROC curve was more favorable for the PASHOS Test, although differences were only statistically significant with the 

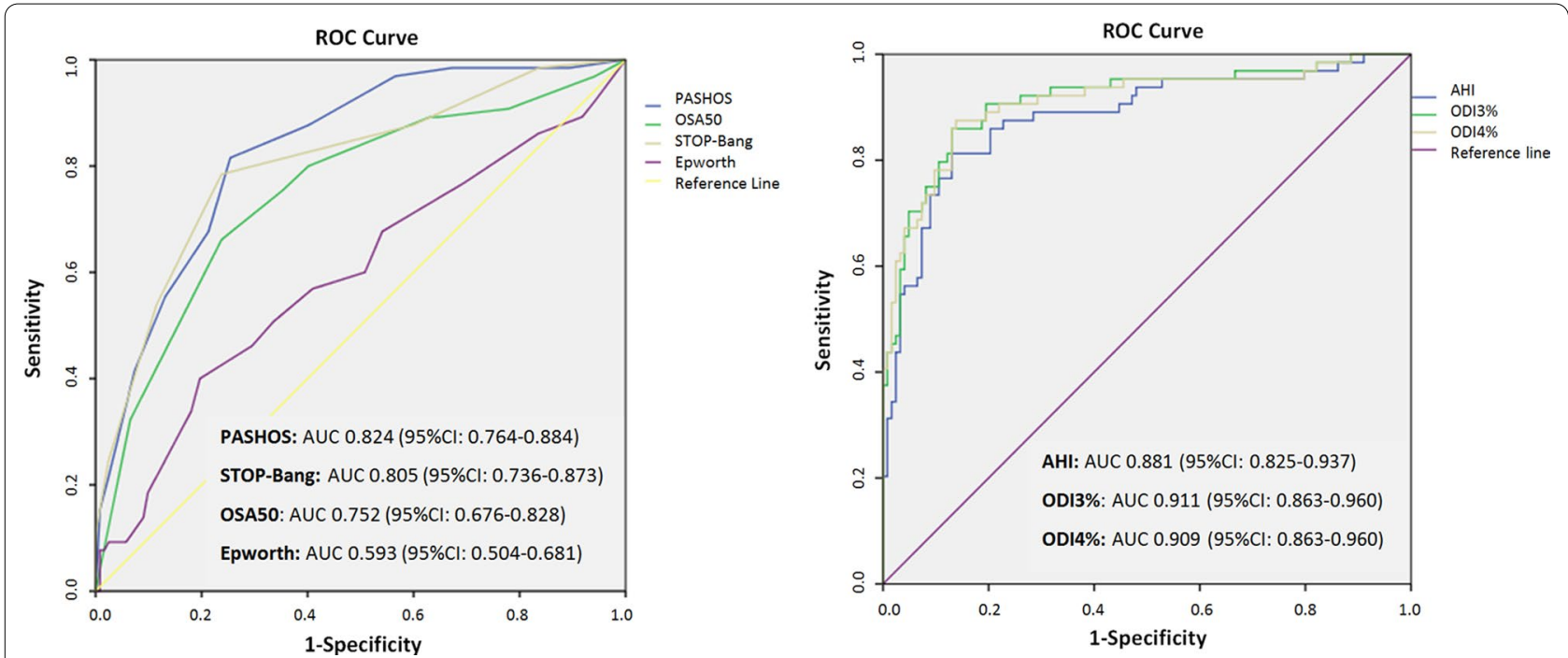

Fig. 2 Diagnostic accuracy of the PASHOS Test for a cut-off value of $\geq 5$ and different study questionnaires (left panel) as well as variables obtained with the home sleep apnea test (right panel) (AUC: area under the ROC curve; Cl: confidence interval; AHI: apnea-hypopnea index; ODI3\%: oxygen desaturation index of 3\%; ODI4\%: oxygen desaturation index of 4\%)

Epworth sleepiness scale. The sensitivity, specificity, positive and negative predictive values, and overall diagnostic accuracy for the PASHOS Test as compared to the study questionnaires are shown in Table S3 (Supplementary material). In this comparisons, the PASHOS Test showed the highest sensitivity $(92.6 \%, 95 \%$ CI 83.9-96.8) and negative predictive value (93.1\%, 95\% CI 84.8-97.0).

\section{Model based on home sleep apnea test variables}

The diagnostic accuracy of variables obtained in the HSAT were assessed and included in the logistic regression model. As shown in Fig. 2, the AUC of the ROC curve for ODI3\% $(0.911,95 \%$ CI $0.863-0.960)$ was slightly higher than those corresponding to the AHI and ODI4\%. The diagnostic accuracy of the PASHOS model in relation to cut-off values of the ODI3\% between $\geq 10$ and $\geq 30$ is shown in Table S3 (Supplementary material). The sensitivity of the PASHOS model was $85.5 \%$ (95\% CI 74.7-92.1) and the specificity $67.8 \%$ (95\% CI 55.1-78.3) with an ODI3\% of $\geq 15$.

When the dependent variable in the logistic regression model was an $\mathrm{AHI} \geq 30$ obtained in the final respiratory polygraphy or conventional polysomnography, it was shown that the model included the same predictive variables and very similar values of the AUC of the ROC curve (0.819, 95\% CI 0.753-0.885).

Based on the final decision taken by sleep specialists, the PASHOS Test with a cut-off value of $\geq 5$ classified correctly 67 patients $(34.5 \%)$ who were non-candidates for CPAP therapy, with a further 40 patients $(20.6 \%)$ when an ODI3\% of $\geq 15$ was added (Table 4 ).

\section{Discussion}

This study proposes a two-stage screening model for OSA developed in non-selected patients attended to in the primary care setting. This model includes a questionnaire (PASHOS Test) based on three clinical variables (BMI, neck circumference, breathing pauses during sleep) that in case of positivity (cut-off $\geq 5$ points) is complemented by a HSAT. This model, easy to use in the clinical setting, has been able to identify patients at high risk of severe OSA who are candidates for CPAP treatment and

Table 4 Classification of patients according to results of the PAHOS Test alone and combined with ODI3\%

\begin{tabular}{lll}
\hline Variable & $\begin{array}{l}\text { Final indication of CPAP } \\
\text { treatment by sleep } \\
\text { specialists }\end{array}$ & Total patients \\
\cline { 2 - 3 } No Yes & \\
\hline
\end{tabular}

\section{PASHOS Test $\geq 5$}

CPAP treatment

$\begin{array}{llll}\text { No } & 67(34.5 \%) & 5(2.6 \%) & 72 \\ \text { Yes } & 59(30.4 \%) & 63(32.5 \%) & 122 \\ \text { Total patients } & 126 & 68 & 194\end{array}$

PASHOS model (Test $\geq 5$ and $\mathrm{ODI} 3 \% \geq 15)$

CPAP treatment

$\begin{array}{llll}\text { No } & 40(33.1 \%) & 10(7.4 \%) & 50 \\ \text { Yes } & 19(15.7 \%) & 53(43.8 \%) & 72 \\ \text { Total patients } & 59 & 63 & 122\end{array}$

CPAP: continuous positive airway pressure; ODI3\%: oxygen desaturation index of $3 \%$ 
should be referred to a sleep unit with a diagnostic accuracy higher than $80 \%$. On the other hand, the use of the model would prevent referral to the sleep unit for $55.1 \%$ of patients with low to moderate risk of OSA. These patients could continue to be attended to in primary care, as a similar management model to other chronic diseases such as asthma or COPD.

Patients were recruited in the primary care setting independent of the reason for consultation and suspicion of OSA. In a second stage, the HSAT was performed in all patients in the OSA high-risk category of Berlin questionnaire and, randomly, 1 out of 2 patients in the lowrisk category. However, results are unlikely to be affected by this randomization, since differences between patients randomized to or not to the sleep study were not found. Our approach is similar to the two-stage model developed by Chai-Coetzer et al. [14] based on 157 patients attending their primary care physician, for any reason, at six primary care clinics in rural and metropolitan regions of South Australia. The screening questionnaire in this study included snoring, waist circumference, witnessed apneas and age, and was followed by a HSAT. This twostage diagnostic model showed a sensitivity of $97 \%$ and specificity of $87 \%$ [14]. In this study, as in other previous studies carried out in selected populations $[15,16]$, the predictive capacity of the model was higher, which may be explained by the fact that they included a HSAT in all patients, independently of the clinical variables. In our opinion, the indication of HSAT without any previous clinical filter may impose a work overload for primary care, transferring the problem of waiting lists to this setting and limiting its applicability. Other models of integrated management of patients with high clinical probability of OSA in primary care have been validated, with non-inferior mid-term results to conventional management in specialized sleep units [17-21]. These results, however, although they offer evidence that non-sleep specialists are capable of providing care to patients with OSA, have been questioned for difficulties of implementation in real-world clinical practice given the work overload in primary care [29].

The two-stage screening model proposed in the present study, includes a short, simple and easy to administer questionnaire (PASHOS Test) with a high sensitivity (93\%) and negative predictive value of 93\% that, in practice, correctly identified subjects at low risk of OSA in $34.5 \%$ of the study sample. The association of the PASHOS Test with ODI3\% in a second stage increases the specificity and positive predictive value of the model, avoiding referral to sleep specialists to further $21 \%$ of patients. The PASHOS Test includes only three variables but shows sensitivity and negative predictive values similar or slightly higher than clinical questionnaires usually recommended for OSA screening, such as the Berlin questionnaire [10], OSA50 [14], and STOP-Bang [11], and clearly higher than the Epworth sleepiness scale, which shows a high specificity but a low sensitivity for detecting OSA [12].

The HSAT was performed using a 2-channel monitor with a nasal cannula for airflow measure and oximetry. In agreement with data reported in the study of ChaiCoetzer et al. [14], the ODI3\% was the parameter with the highest diagnostic reliability. The primary care nurse assessed the quality of sleep studies. The studies were allowed to be repeated in case of poor signaling acquisition or even discarded when invalid recording.

The logistic regression model was calculated according to decision of treatment with CPAP (yes/no). However, this decision may include a subjective component so the AUC of the ROC curve was also calculated taking the $\mathrm{AHI} \geq 30$ as severe OSA obtained in the gold-standard sleep studies. The AUC obtained in this model was very similar, which supports the usefulness of the two-stage model for selecting candidates for CPAP treatment and patients with severe OSA according to AHI.

Strengths of the study include the multicenter design and the fact that the inclusion of patients was not limited to those with a pretest high clinical probability of OSA, so that the results obtained can be applicable to a large phenotype spectrum of patients, but considering the limitations of the study. The limitations include the eligibility criterion of an upper age range of 75 years, which excludes a substantial percentage of patients attended to in primary care. Patients with a previous clinical diagnosis of insomnia are also excluded, which may have contributed to the underdiagnosis of patients with OSA primarily with complaints of sleep disruption, and it is already known the existence of a clinical cluster of OSA related to a high prevalence of hypertension, diabetes, and cardiovascular disease [30]. Also, in contrast to other studies [14-19, 21], the definite diagnosis was not made using polysomnography in all patients [22]. Although respiratory polygraphy may underestimate the diagnosis of OSA, our model was adapted to routine clinical practice and recommendations of current clinical practice guidelines [27].

\section{Conclusion}

This two-stage screening model that includes a short clinical questionnaire (PASHOS Test) and results obtained by a HSAT, is a useful approach in which primary care professionals have an important role in the management of OSA. With a previous adequate training program and in coordination with sleep specialists, unnecessary referrals of patients who are non-candidates for CPAP with mildmoderate OSA could be prevented. 


\begin{abstract}
Abbreviations
AHI: Apnea-hypopnea index; AUC: Area under the curve; BMI: Body mass index; Cl: Confidence interval; COPD: Chronic obstructive pulmonary disease; CPAP: Continuous positive airway pressure; CT90\%: Percentage of time with oxygen saturation below 90\%; FEV1: Forced expiratory volume in $1 \mathrm{~s}$; FVC: Forced vital capacity; HSAT: Home sleep apnea test; ODI3\%: Oxygen desaturation index of 3\%; ODI4\%: Oxygen desaturation index of 4\%; OSA: Obstructive sleep apnea; PSG: Polysomnography; ROC: Receiver operating characteristic; RP: Respiratory polygraphy; SD: Standard deviation; $\mathrm{SpO}_{2}$ : Peripheral oxygen saturation; VIF: Variance inflation factor.
\end{abstract}

\section{Supplementary Information}

The online version contains supplementary material available at https://doi. org/10.1186/s12890-022-01827-0.

Additional file 1: Table S1. Characteristics of patients at low risk of OSA based on scores of the Berlin questionnaire randomized or not randomized to home sleep apnea test (HSAT). Table S2. PASHOS Test. Table S3. Diagnostic accuracy of the PASHOS Test as compared with the study questionnaires and with the addition of ODI3\%.

\section{Acknowledgements}

The authors thank Marta Pulido, MD, for editing the manuscript and editorial assistance.

PASHOS Working Group: Leandra Domínguez Olivera (Equip d'Atenció Primària Encants, Centre d'Atenció Primària (CAP) Maragall, Institut Català de la Salut); Pepi Valverde Trillo (Àrea Bàsica de Salut (ABS) Gaudí, Consorci Sanitari Integral); Ma Ángeles Santos Santos and Ma del Mar Farga Martínez (CAP Chafarinas, Institut Català de la Salut); Montserrat Reverté Simó (CAP Trinitat Vella, Institut Català de la Salut); and Núria Argemí Saburit, Casimira Medrano Medrano, and Marineus Puig García (CAP El Clot, Institut Català de la Salut), Barcelona, Spain.

\section{Authors' contributions}

Design: P.P., M.A.LI., A.M.P.P., C.S., X.F., J.J., G.S., P. LI., J.I.A., J.B., N.G., A.M.F., and M.M. Acquisition of data: P.P., M.A.LI., A.M.P.P., C.S., X.F., J.J., G.S., P. LI., J.I.A., J.B. N.G., A.M.F., and M.M. Analysis of data: P.P. and M.M.; Interpretation of data: P.P., M.A.LI., A.M.P.P., C.S., X.F., J.J., G.S., P. LI., J.I.A., J.B., N.G., A.M.F., and M.M. Writing the manuscript: P.P. and M.M. Approval of the version to be published and agreement to be accountable for all aspects of the work: all authors.

\section{Funding}

The Spanish Society of Pneumology and Thoracic Surgery (SEPAR), the Catalan Society of Pneumology (SOCAP) and the Fondo de Investigaciones Sanitarias (FIS) (PI 14/01985) funded this study to acquire the necessary devices, to design and maintain the database, for statistical advice and data analysis. This was not an industry-backed study.

\section{Availability of data and materials}

Study data are available from the corresponding author upon request.

\section{Declarations}

Ethics approval and consent to participate

This project was approved by the Clinical Research Ethics Committee of the Hospital de la Santa Creu i Sant Pau. Committee's reference number: IIBSP-PAS-2013-151. Written informed consent to participate in the study was obtained from all patients.

\section{Consent for publication}

Written informed consent was obtained from all patients. In this manuscript there is no personal or clinical data of the participants that compromises anonymity.

\section{Competing interests}

The first author and none of the other authors have any affiliations or financial involvement that conflict with the material presented in this study.

\section{Author details}

${ }^{1}$ Sleep Unit, Department of Respiratory Diseases, Hospital de La Santa Creu I Sant Pau, Universitat Autònoma de Barcelona, Barcelona, Spain. ${ }^{2}$ Department of Medicine, Universitat Autònoma de Barcelona, Barcelona, Spain. ${ }^{3}$ Equip d'Atenció Primària Encants, Centre d'Atenció Primària (CAP) Maragall, Institut Català de La Salut, Barcelona, Spain. ${ }^{4}$ CAP Chafarinas, Institut Català de La Salut, Barcelona, Spain. ${ }^{5}$ Sleep Unit, Service of Pneumology, Hospital Universitari Vall d'Hebron, Universitat Autònoma de Barcelona, Barcelona, Spain. ${ }^{6}$ Centro de Investigación Biomédica en Red Enfermedades Respiratorias (CIBERES), Instituto de Investigación Carlos III, Madrid, Spain. 'Àrea Bàsica de Salut Gaudí, Consorci Sanitari Integral, Barcelona, Spain. ${ }^{8}$ Sleep Unit, Department of Respiratory Medicine, Parc de Salut Mar-IMIM, Hospital del Mar, Barcelona, Spain. ${ }^{9}$ Service of Pneumology, Hospital Dos de Maig, Consorci Sanitari Integral, Barcelona, Spain. ${ }^{10}$ CAP Trinitat Vella, Institut Català de La Salut, Barcelona, Spain. ${ }^{11}$ CAP El Clot, Institut Català de La Salut, Barcelona, Spain.

Received: 11 October 2021 Accepted: 16 December 2021

Published online: 15 January 2022

\section{References}

1. Benjafield AV, Ayas NT, Eastwood PR, Heinzer R, Ip MSM, Morrell MJ, et al. Estimation of the global prevalence and burden of obstructive sleep apnoea: a literature-based analysis. Lancet Respir Med. 2019;7(8):687-98.

2. Tietjens JR, Claman D, Kezirian EJ, de Marco T, Mirzayan A, Sadroonri B, et al. Obstructive sleep apnea in cardiovascular disease: a review of the literature and proposed multidisciplinary clinical management strategy. J Am Heart Assoc. 2019;8(1):e010440.

3. Punjabi NM, Caffo BS, Goodwin JL, Gottlied DJ, Newman AB, O'Connor GT, et al. Sleep-disordered breathing and mortality: prospective cohort study. PLoS Med. 2009;6(8):e1000132.

4. Campos-Rodriguez F, Martinez-Garcia MA, Martinez M, Duran-Cantolla J, De La Penã M, Masdeu MJ, et al. Association between obstructive sleep apnea and cancer incidence in a large multicenter spanish cohort. Am J Respir Crit Care Med. 2013;187:99-105.

5. Lajoie AC, Lafontaine A-L, Kimoff RJ, Kaminska M. Obstructive sleep apnea in neurodegenerative disorders: current evidence in support of benefit from sleep apnea treatment. J Clin Med. 2020;9:297.

6. Suárez M, Osorio J, Torres M, Montserrat JM. Should the diagnosis and management of OSA move into general practice? Breathe. 2016;12(3):243-7.

7. Donovan LM, Shah A, Chai-Coetzer CHL, Barbé F, Ayas NT, Kapur VK. Redesigning care for OSA. Chest. 2020;157(4):966-76.

8. Rotenberg BW, George CF, Sullivan KM, Wong E. Wait times for sleep Apnea care in Ontario: a multidisciplinary assessment. Can Respir J. 2010;17(4):170-4.

9. Patil SP, Ayappa IA, Caples SM, John Kimoff R, Patel SR, Harrod CG. Treatment of adult obstructive sleep apnea with positive airway pressure: an American academy of sleep medicine clinical practice guideline. J Clin Sleep Med. 2019;15(2):335-43.

10. Netzer NC, Stoohs RA, Netzer CM, Clark K, Strohl KP. Using the Berlin Questionnaire to identify patients at risk for the sleep apnea syndrome. Ann Intern Med. 1999;131:485-91.

11. Chung F, Abdullah HR, Liao P. Stop-bang questionnaire: a practical approach to screen for obstructive sleep apnea. Chest. 2016;149(3):631-8.

12. Miller JN, Berger AM. Screening and assessment for obstructive sleep apnea in primary care. Sleep Med Rev 2016:41-51.

13. Duarte RLM, Rabahi MF, Magalhães-da-Silveira FJ, De Oliveira-E-Sá TS, Mello FCQ, Gozal D. Simplifying the screening of obstructive sleep apnea with a 2-item model, no-apnea: a cross-sectional study. J Clin Sleep Med. 2018;14(7):1097-107.

14. Chai-Coetzer CL, Antic NA, Rowland LS, Catcheside PG, Esterman A, Reed RL, et al. A simplified model of screening questionnaire and home monitoring for obstructive sleep apnoea in primary care. Thorax. 2011;66(3):213-9.

15. Gurubhagavatula I, Maislin G, Pack Al. An algorithm to stratify sleep apnea risk in a sleep disorders clinic population. Am J Respir Crit Care Med. 2001;164(101):1904-9. 
16. Mulgrew AT, Fox N, Ayas NT, Ryan CF. Diagnosis and initial management of obstructive sleep apnea without polysomnography: A randomized validation study. Ann Intern Med. 2007;146(3):157-66.

17. Antic NA, Buchan C, Esterman A, Hensley M, Naughton MT, Rowland S, et al. A randomized controlled trial of nurse-led care for symptomatic moderate-severe obstructive sleep apnea. Am J Respir Crit Care Med. 2009;179(6):501-8.

18. Sánchez-De-La-Torre M, Nadal N, Cortijo A, Masa JF, Duran-Cantolla J, Valls $\mathrm{J}$, et al. Role of primary care in the follow-up of patients with obstructive sleep apnoea undergoing CPAP treatment: a randomised controlled trial. Thorax. 2015;70(4):346-52.

19. Chai-Coetzer CL, Antic NA, Rowland LS, Reed RL, Esterman A, Catcheside $P G$, et al. Primary care vs specialist sleep center management of obstructive sleep apnea and daytime sleepiness and quality of life: a randomized trial. JAMA. 2013;309(10):997-1004.

20. Tarraubella N, Sánchez-De-La-Torre M, Nadal N, De Batlle J, Benítez I, Cortijo A, et al. Management of obstructive sleep apnoea in a primary care vs sleep unit setting: a randomised controlled trial. Thorax. 2018;73(12):1152-60.

21. Ángeles Sánchez-Quiroga M, Corral J, Gómez-de-Terreros FJ, CarmonaBernal C, Isabel Asensio-Cruz M, Cabello M, et al. Primary care physicians can comprehensively manage patients with sleep apnea a noninferiority randomized controlled trial. Am J Respir Crit Care Med. 2018;198(5):648-56.

22. Mayos M, Peñacoba P, Pijoan AMP, Santiveri C, Flor X, Juvanteny J, et al. Coordinated program between primary care and sleep unit for the management of obstructive sleep apnea. Npj Prim Care Respir Med 2019;29(1):39

23. Peñacoba P, Antònia Llauger M, Fortuna AM, Flor X, Sampol G, Pijoan AMP, et al. Primary care and sleep unit agreement in management decisions for sleep apnea: a prospective study in Spain. J Clin Sleep Med. 2020;16(9):1579-89.

24. Walker NA, Sunderram J, Zhang P, Lu S-E, Scharf MT. Clinical utility of the Epworth sleepiness scale. Sleep Breath. 2020;24(4):1759-65.

25. Netzer NC, Hoegel JJ, Loube D, Netzer CM, Hay B, Alvarez-Sala R, et al. Prevalence of symptoms and risk of sleep apnea in primary care. Chest. 2003;124(4):1406-14.

26. Lloberes P, Duran-Cantolla J, Martinez-Garcia MA, Marin JM, Ferrer A, Corral J, et al. Diagnosis and treatment of sleep apnea-hypopnea syndrome. Spanish Society of Pulmonology and Thoracic Surgery. Arch Bronconeumol. 2011;47:143-56.

27. Kapur VK, Auckley DH, Chowdhuri S, Kuhlmann DC, Mehra R, Ramar K, et al. Clinical practice guideline for diagnostic testing for adult obstructive sleep apnea: an American academy of sleep medicine clinical practice guideline. J Clin Sleep Med. 2017;13:479-504.

28. Yoo W, Mayberry R, Bae S, Singh K, Peter He Q, Lillard JW. A study of effects of multicollinearity in the multivariable analysis. Int J Appl Sci Technol. 2014;4:9-19.

29. Kuna ST. Diagnosis and management of patients with obstructive sleep apnea in primary care. Ready or not? Am J Respir Crit Care Med. 2018;198:557-8

30. Keenan BT, Kim J, Singh B, et al. Recognizable clinical subtypes of obstructive sleep apnea across international sleep centers: a cluster analysis. Sleep. 2018;41(3):Zs×214.

\section{Publisher's Note}

Springer Nature remains neutral with regard to jurisdictional claims in published maps and institutional affiliations.

Ready to submit your research? Choose BMC and benefit from:

- fast, convenient online submission

- thorough peer review by experienced researchers in your field

- rapid publication on acceptance

- support for research data, including large and complex data types

- gold Open Access which fosters wider collaboration and increased citations

- maximum visibility for your research: over $100 \mathrm{M}$ website views per year

At BMC, research is always in progress.

Learn more biomedcentral.com/submissions 